\title{
Implied Correlation Index: an Application to Economic Sectors of Commodity Futures and Stock Markets
}

\author{
Krzysztof Echaust ${ }^{1}$, Malgorzata Just ${ }^{2}$ \\ ${ }^{1}$ Poznan University of Economics and Business \\ Aleje Niepodleglosci 10, 61-875 Poznan, Poland \\ E-mail.k.echaust@ue.poznan.pl \\ ${ }^{2}$ Poznan University of Life Sciences \\ Wojska Polskiego 28, 60-637 Poznan, Poland \\ E-mail.malgorzata.just@up.poznan.pl
}

cross $^{\text {ref }}$ http://dx.doi.org/10.5755/j01.ee.31.1.22247

\begin{abstract}
An implied correlation index (ICI) measures the average correlation between all constituents of the portfolio. The concept of the index is similar to that of the S\&P500 implied correlation index, but it is based on volatility estimation instead of option-implied volatility. The objective of the study is to examine the dynamics and properties of the implied correlation estimates within various economic sectors of the stock and commodity markets. We explore three commodity futures markets: metals, energy, agriculture, and five stock markets: basic materials, financials, industrials, oil \& gas and technology over the period of 2006-2017. In order to capture the dynamic character of the implied correlation we propose to take into account the GARCH type approaches to calculate volatility and Value at Risk estimates of considered assets and use them in implied correlation estimates. We also found statistical properties of the implied correlation indices. The implied correlation for most sectors is both time-varying and market-state-dependent. Assets in stock sectors are on average much more dependent than assets in commodity sectors. The implied correlation exhibits clustering properties, long memory, asymmetry and co-movement with volatility. Using the Granger causality test we showed that the impact of ICI on volatility is highly statistically significant. These results provide some useful practical implications for investors and financial institution how to estimate and control time-varying dependence between the assets in the investment portfolio.
\end{abstract}

Keywords: Implied Correlation Index; VaR-Implied Correlation Index; Stylised Facts; Portfolio; Stocks; Commodities.

\section{Introduction}

According to the modern portfolio theory, risk of portfolio may be reduced to the systematic risk level by diversifying a portfolio by incorporating various assets (Markowitz, 1952). The key factor responsible for the effectiveness of a diversification is the correlation coefficient. The lower the correlation, the greater the potential for risk reduction through diversification, because a decrease in one asset may be offset by an increase in other assets. Correlations rise as an effect of investors' rush to buy or sell stocks all at once. Skintzi and Refenes (2005) indicate three stylised facts concerning correlation between financial assets. These are long memory, negative asymmetry between stock returns and correlation, and correlation and volatility co-movement. Thanks to them correlation may supply investors with valuable information concerning the current or future state of the market.

Although Pearson correlation coefficient is the most popular measure of dependence, in a portfolio it has several disadvantages. Correlations vary in time, especially during market downturns most assets tend to decrease in value when investors sell off their assets. This fact is in line with the co-movement of correlation and volatility documented e.g. by Longin and Solnik (1995), Siegel (1997), Walter and Lopez (2000). This property hinders maintenance of diversified portfolios over time. Especially during crises well-diversified portfolios become much more risky as the effect of correlations increase. In modelling of time-varying correlations between assets, we can use multivariate volatility models, e.g. multivariate GARCH (M-GARCH) models (Bauwens et al., 2006). However, problems with estimating a large number of parameters in these models are found for portfolios consisting of more than half a dozen assets. The Dynamic Conditional Correlation model (DCC) is often used in the practice of parsimonious parametric models (Engle, 2002). This model allows estimating conditional correlations for portfolios comprising a larger number of components. A disadvantage of the DCC model is connected with the limitations imposed on the multivariate joint distribution, defining the structure of dependence between assets and marginal distributions of these assets.

Another problem in using the Pearson correlation is related with the fact that it is a natural dependence measure only for elliptically distributed assets (McNeil et al., 2005). The most popular elliptical distributions are Gaussian and Student's $t$-distributions. When other distribution classes are considered, the problem of non-subadditivity risk measures appears and risk measured by Value at Risk (VaR) may be higher for the whole portfolio than for the sum of risks of individual assets.

Another issue stems from the fact that the correlation is a measure between pairs of assets. In contrast to volatility, which may be monitored and analysed for portfolios as a market fear indicator (e.g. VIX or conditional heteroscedastic volatility), it is difficult to do the same for correlations. 
Correlation is a measure of dependence between two variables and for an $n$-asset portfolio we have $\left(n^{2}-n\right) / 2$ correlations. Thus it is impossible to control all of them. Engle and Kelly (2012) proposed Dynamic Equicorrelation (DECO), which greatly simplifies multivariate specifications of the portfolio dependence structure. The DECO estimates only one correlation coefficient instead of averaging correlations after estimating them. However, this model may be a poor tool when describing raw returns of assets and should be applied to GARCH standardized residuals (Engle \& Kelly, 2012).

In 2009 CBOE introduced the implied correlation index (ICJ) as an analogue to the VIX index for volatility. ICJ measures the average correlation between assets of the S\&P500 index. It is based on options written on the 50 largest companies in the index. The ICJ has been found to have predictive power when it comes to the S\&P500 index. Zhou (2013) investigated the role for the ICJ index in predicting the S\&P500 weekly return volatility. He found a close long-term relationship between the current information set of the S\&P500 index and ICJ weekly returns. Fink and Geppert (2016) analysed the dependence structure of the German DAX index. They showed that the inclusion of the implied correlation may effectively improve implied volatility forecasting. In turn, Driessen et al. (2009) stated that implied correlations have a remarkable predictive power for future stock market excess returns, especially at the 6-month and 1-year horizons. Together with variance risk premiums, implied correlations explain as much as $15 \%$ of the observed variation in future aggregate stock returns. The high explanatory power of the implied correlation was stressed by Skintzi and Refenes (2005). In comparison to a historical forecast based on the average pair-wise correlation of the correlation index, the implied correlation index exhibits a stronger relationship to the future correlation index. Härdle and Silyakova (2014) investigated correlation based trade strategies. They showed that using the correlation forecast one can improve the original dispersion strategy, which consists in selling the variance of the basket (DAX) and buying variances of basket constituents.

A different, but very similar approach is represented by the implied correlation concept based on volatility estimation instead of option-implied volatility. The concept was proposed by Cambell et al. (2002) and has been analysed further by other authors. Cotter and Longin (2011) investigated the impact of the portfolio weights, the type of position, the frequency of data and the probability level on implied correlations. They documented that the implied correlation tends to deviate from the Pearson correlation and to be higher for long positions than for short positions. The implied correlation increases with the confidence level of $\mathrm{VaR}$ for a long position and decreases with the confidence level of VaR for a short position. Implied correlation tends to decrease overall with the frequency of price changes. The most interesting finding is that the implied correlation behaves in a similar way for different portfolio weights. It means that investors obtain a highly informative indicator free from the choice of portfolio weights.

Volatility and correlation are central to many applied issues in finance, ranging from asset pricing and asset allocation to risk management (Andersen et al., 1999). Although there are many studies on volatility (e.g.
Lamoureux \& Lastrapes, 1990; Campbell \& Hentschel, 1992; Engle \& Ng, 1993; Andersen, 1996; Solnik et al., 1996; Ramchand \& Susmel, 1998; Andersen et al., 2000; Bollerslev et al., 2000; Ang \& Chen, 2002; Bartram \& Wang, 2005; Skintzi \& Refenes, 2005; Girard \& Biswas, 2007; Daouck \& Ng, 2011; Dai et al., 2015; Naik \& Padhi, 2015), the literature on the implied correlation is sparse, especially empirical studies. This paper presents an empirical study conducted on the implied correlation in various commodity and stock sectors. We take into account data from the period of 2006-2017. We selected a relatively long period of time in order to explore the pattern and behaviour of implied correlations in selected sectors for various states of the market.

In this study we focus on the measure of dependence that eliminate the computational and presentational difficulties of high-dimension systems, since the timevarying correlation between assets is expressed by one number at a point in time. The objective of the study is to examine the dynamics and properties of the implied correlation index estimates within various economic sectors of the stock and commodity markets.

Our contribution to literature is the following: firstly, we propose to calculate the dynamic version of the implied correlation. We use GARCH and GARCH-Filtered Historical Simulation approaches to estimate volatility and Value at Risk in the implied correlation formula. Such an approach allows us to measure the implied correlation in a dynamic way. We compare the implied correlation in the selected sector with the average of the Pearson correlation for asset pairs in this sector. Secondly, we extend the state of art by considering the properties of dynamic implied correlation. We detect the clustering properties, long memory and asymmetry of implied correlation, and its comovement with volatility. Thirdly, we conduct the empirical study for stock and commodity portfolios. We find higher homogeneity, in the stock sectors than in the commodity sectors. Moreover, we find different properties of implied correlation indices of stocks and commodities. Our findings shed a new light for a portfolio diversification problem, its effectiveness and stability.

The remainder of the paper is organized as follows: section 2 presents the basics of the implied correlation, while section 3 shows the data used in the empirical study. In section 4 the empirical results are presented, while the last section gives the conclusions.

\section{Implied Correlation Index}

Let $\boldsymbol{r}$ denote the vector of asset returns and $r_{p}=\boldsymbol{w}^{\prime} \boldsymbol{r}$ is the return of the $n$-asset portfolio with weights $\boldsymbol{w}>\mathbf{0}$ and $\boldsymbol{w}^{\prime} \mathbf{1}=1$. If returns follow an elliptical distribution, variance of the portfolio is equal to $\sigma_{p}^{2}=\boldsymbol{w}^{\prime} \boldsymbol{\Sigma} \boldsymbol{w}=$ $\sum_{i=1}^{n}\left(w_{i} \sigma_{i}\right)^{2}+2 \sum_{i=1}^{n-1} \sum_{j=i+1}^{n} w_{i} \sigma_{i} w_{j} \sigma_{j} \rho_{i j}$, where $\mathbf{\Sigma}$ denotes the covariance matrix, $\sigma_{i}$ is the volatility of the $i$-th portfolio component and $\rho_{i j}$ is the pair-wise correlation of portfolio components. Implied correlation $\rho$ measures the average correlation of the portfolio, thus variance of the portfolio can be rewritten as follows:

$$
\sigma_{p}^{2}=\sum_{i=1}^{n}\left(w_{i} \sigma_{i}\right)^{2}+2 \rho \sum_{i=1}^{n-1} \sum_{j=i+1}^{n} w_{i} \sigma_{i} w_{j} \sigma_{j}
$$


By solving the above equation with respect to $\rho$ we obtain a close-form solution (implied correlation index, ICI):

$$
\rho=\frac{\sigma_{p}^{2}-\sum_{i=1}^{n}\left(w_{i} \sigma_{i}\right)^{2}}{2 \sum_{i=1}^{n-1} \sum_{j=i+1}^{n} w_{i} \sigma_{i} w_{j} \sigma_{j}}
$$

The analogue formula may be obtained for the $\alpha$ quantile of returns distribution (VaR-implied correlation index, VaR-ICI) (Cambell et al., 2002):

$$
\rho_{\alpha}=\frac{q_{\alpha, p}^{2}-\sum_{i=1}^{n}\left(w_{i} q_{\alpha, i}\right)^{2}}{2 \sum_{i=1}^{n-1} \sum_{j=i+1}^{n} w_{i} q_{\alpha, i} w_{j} q_{\alpha, j}} .
$$

The implied correlation is invariant with respect to weights and the confidence level for elliptical distribution, but not for other classes. The greatest drawback of $\rho_{\alpha}$ is that estimators (2) and (3) do not fulfill the basic property for the correlation coefficient, i.e. $\left|\rho_{\alpha}\right| \leq 1$. Bourgoin (2001) showed that if the correlation matrix is positive semidefinite, for sufficiently large baskets the above property holds. However, if one considers portfolios that are not sufficiently diversified the problem must be eliminated. Thus Mittnik (2014) proposed to solve the optimisation problem by selecting the portfolio weights so that a correlation exceeding one is avoided. He analysed a portfolio of 30-stocks belonging to the German DAX index in the period of 2003-2013. Liu (2016) extended the VaR approach for the Expected Shortfall case avoiding the problem of non-subadditivity. He showed that the difference in the implied correlations from the application of different weight vectors varies slightly in the tails, but differs greatly around the centre of distribution. The problem disappears when the Expected Shortfall-implied correlation instead of $\mathrm{VaR}$ is analysed. The simplest way to deal with the problem of non-subadditivity is to use a truncated version of (3) (see Mittnik, 2014):

$$
\rho_{\alpha}^{*}=\left\{\begin{array}{lr}
1, & q_{\alpha, p} \geq \sum_{i=\mathbf{1}}^{n} w_{i} q_{\alpha, i} \\
\rho_{\alpha}, & \text { otherwise }
\end{array}\right.
$$

Analogously we can use a truncated version of (2).

\section{Data Description}

The data set studied comprised 15 futures on commodities and 44 stocks. We considered three classes of commodities: energy, metals, agriculture, and stocks from five economic sectors: basic materials, financial, industrials, oil \& gas and technology. Constituents of particular commodity classes are as follows: energy - crude oil, heating gas, natural gas; metals - gold, silver, platinum, copper; agriculture - maize, wheat, soybeans, soybean oil, cotton, sugar, cocoa and coffee. The basic materials sector is a group of stocks of companies involved in the discovery and processing of raw materials. This sector includes mining and refining of metals, chemical and forestry products. The financial sector is a group of companies that provide financial services to retail and commercial customers. In turn, the industrial sector is a category of stocks of companies involved in producing goods used in the manufacturing and construction industries. The next analysed sector is the sector comprising a category of companies related to the oil and gas industry. The technology sector represents a group of stocks of companies relating to the research, development and distribution of technologically based services and goods. Individual stocks were included in the analysis if they were traded over the entire horizon of 2006-2017 and were members of the S\&P Dow Jones Index at the end of 2017. Futures on a commodity were included if they were traded over the entire horizon of 2006-2017 and were members of the Thomson Reuters Equal Weight Commodity Index (with the exception of live cattle and lean hogs). All assets were listed on the U.S. exchanges. We selected these assets because they represent large and liquid markets. The data set is obtained from EIKON Thomson Reuters ${ }^{\circledR}$. The time series consists of daily closing prices and the total number of observations is 3020 for commodities (3022 - energy, 3079 - metals, 3024 - agriculture) and 3020 for stocks, respectively. The calculations are based on daily percentage log-returns. Figure 1 shows the daily returns of stock and commodity equally-weighted portfolios.

Table 1 presents descriptive statistics concerning all asset portfolios used in our study. The highest daily mean return is observed for the technology and industrials, but a median for basic materials. The lowest mean return and median are observed for the energy sector. It is interesting that stocks have a much higher mean return $(0.0295 \%)$ and median $(0.0758 \%)$ than commodities (mean: $0.0065 \%$, median: $0.0311 \%)$. According to the modern portfolio theory, a higher return is linked to a higher investment risk. Standard deviation $(1.47 \%)$ and range $(24.34 \%)$ for stocks is higher than for commodities $(1.07 \%$ and $12.51 \%$, respectively). The riskiest assets are financials with standard deviation of $2.26 \%$ and range equal to $42.67 \%$. The reason is that the period of the study includes two financial crises (the subprime financial crisis and the European sovereign debt crisis). The lowest risk measured by standard deviation and range is observed for agriculture with a range almost 3.5 times lower than for financials. Daily returns are negatively skewed except for financials, technology and energy with skewness near zero. All the stock sectors have kurtosis much greater than normal distribution, but the commodity sectors have kurtosis closer to 0. However, the Jarque-Bera (J-B) test statistics under the null hypothesis of normality clearly indicate that the daily returns are non-normal (Table 1). The ARCH-LM test is applied to find the presence of the $\mathrm{ARCH}$ effect in analysed time series. In all cases ARCHLM test statistics are highly significant and hence these results lead to the estimation of GARCH family models. We conducted the test for lags 5 and 15 as well and we obtained the same results. Figure 2 shows autocorrelations of squared returns. The autocorrelations decay at a very slow rate and remain positive for a substantial number of lags. The autocorrelations for commodities decay slower than for stocks. This result evidences a stronger long memory property in volatility for commodities than for stocks. 

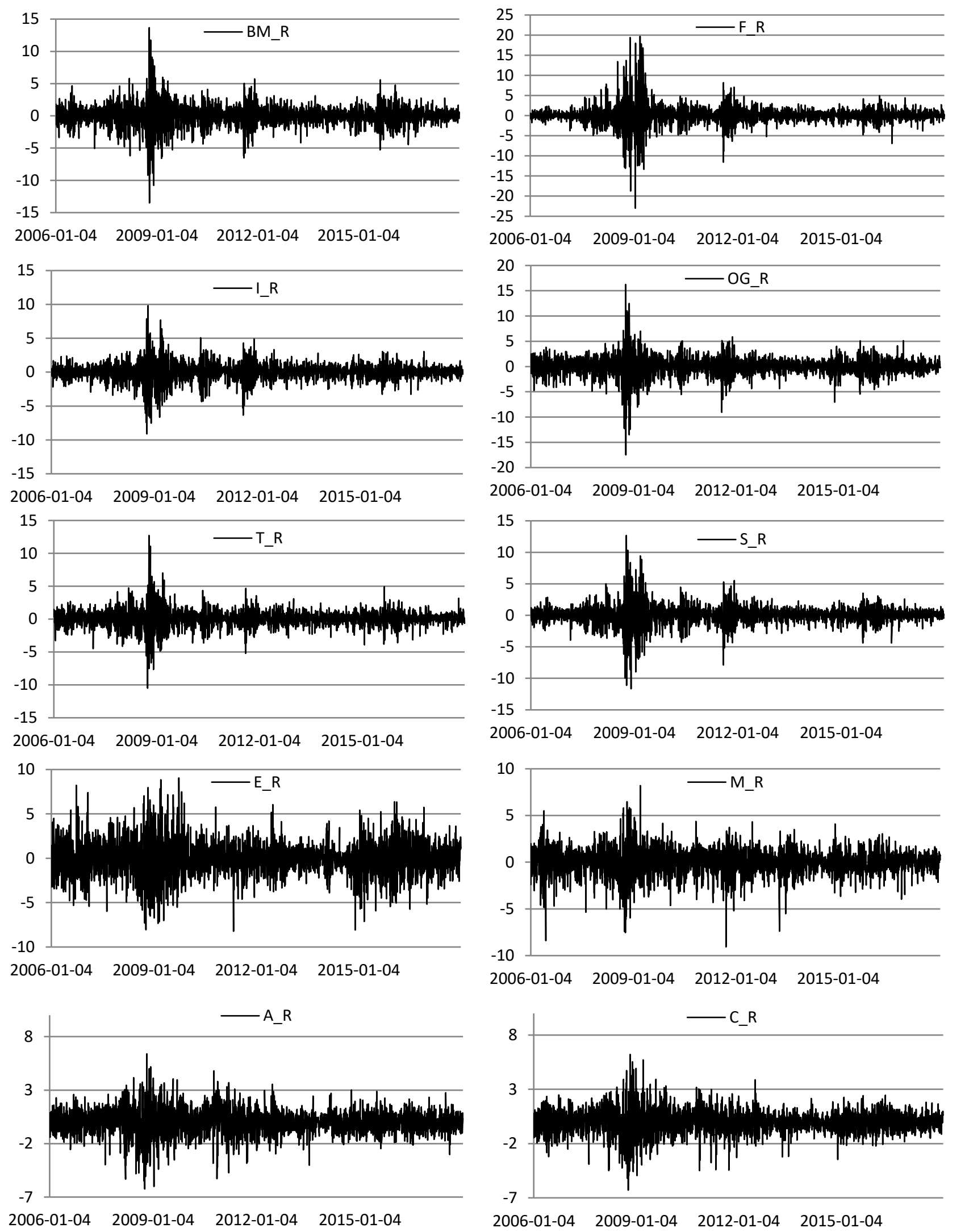

Note: BM-basic materials, $F$-financial, I-industrials, OG-oil \& gas, T-technology, E-energy, $M$ - metals, A-agriculture sectors, $S$ - portfolio of all stocks, $C$ - portfolio of all commodities, $R$ - returns.

Figure 1. Daily Returns of Stock and Commodity Portfolios (\%) 
Descriptive Statistics for Stock and Commodity Portfolio Daily Returns

\begin{tabular}{|c|c|c|c|c|c|c|c|c|c|c|}
\hline Sector & Basic materials & Financials & Industrials & Oil \& gas & Technology & Stocks & Energy & Metals & Agriculture & Commodities \\
\hline Mean (\%) & 0.0278 & 0.0143 & 0.0411 & 0.0225 & 0.0451 & 0.0295 & -0.0130 & 0.0154 & 0.0093 & 0.0065 \\
\hline Median (\%) & 0.0981 & 0.0309 & 0.0891 & 0.0556 & 0.0848 & 0.0758 & -0.0170 & 0.0764 & 0.0158 & 0.0311 \\
\hline Max (\%) & 13.67 & 19.67 & 9.82 & 16.25 & 12.73 & 12.68 & 9.05 & 8.20 & 6.39 & 6.22 \\
\hline Min (\%) & -13.50 & -23.00 & -9.11 & -17.49 & -10.50 & -11.66 & -8.23 & -9.07 & -6.24 & -6.29 \\
\hline Std. Dev. (\%) & 1.62 & 2.26 & 1.26 & 1.84 & 1.27 & 1.47 & 1.92 & 1.37 & 1.14 & 1.07 \\
\hline Skewness & -0.28 & 0.08 & -0.36 & -0.52 & 0.09 & -0.38 & 0.03 & -0.49 & -0.25 & -0.24 \\
\hline Ex. Kurtosis & 8.45 & 18.66 & 6.86 & 10.81 & 10.47 & 11.35 & 1.84 & 4.01 & 2.89 & 3.52 \\
\hline J-B & 8989.84 & 43668.15 & 5958.11 & 14779.71 & 13751.92 & 16225.44 & 423.47 & 2179.69 & 1078.04 & 1583.78 \\
p-values & 0.000 & 0.000 & 0.000 & 0.000 & 0.000 & 0.000 & 0.000 & 0.000 & 0.000 & 0.000 \\
\hline LM(1) & 211.10 & 227.68 & 79.64 & 170.43 & 96.54 & 130.44 & 48.53 & 81.66 & 22.79 & 35.38 \\
p-values & 0.000 & 0.000 & 0.000 & 0.000 & 0.000 & 0.000 & 0.000 & 0.000 & 0.000 & 0.000 \\
\hline LM(10) & 1032.54 & 591.85 & 839.94 & 926.00 & 701.92 & 838.25 & 303.41 & 306.10 & 377.28 & 487.12 \\
p-values & 0.000 & 0.000 & 0.000 & 0.000 & 0.000 & 0.000 & 0.000 & 0.000 & 0.000 & 0.000 \\
\hline
\end{tabular}

Note: J-B - statistic of the Jarque-Bera test for returns, LM(p) - statistic of Engle's (1982) ARCH-LM test with p lags.

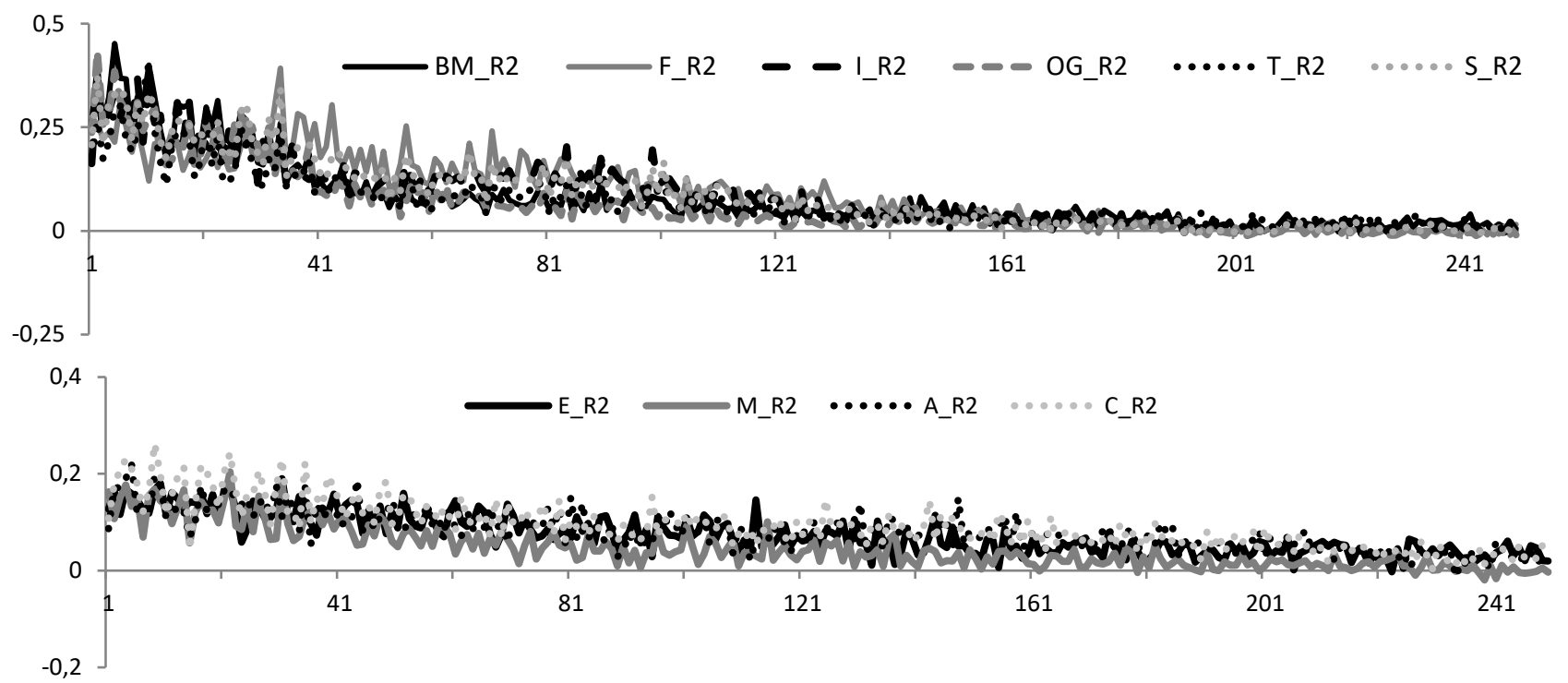

Note: BM-basic materials, $F$-financial, I-industrials, OG-oil \& gas, $T$-technology, E-energy, $M$ - metals, A-agriculture sectors, $S$ - portfolio of all stocks, $C$-portfolio of all commodities, $R 2$ - squares returns.

Figure 2. Autocorrelations of Squared Daily Returns up to 250 Lags

\section{Empirical Study}

In this section we present empirical results of this study. First, we explain the method of estimation of volatility, Value at Risk and the implied correlation followed by the presentation of calculated results. Afterwards we discuss properties of the implied correlation, such as persistence, asymmetry and correlation and volatility co-movement.

\section{Implied Correlation Index for the Stock and Commodity Sectors}

Implied correlation (2) and VaR-implied correlation (3) require weights, volatility or Value at Risk estimates as entry data. Because they are not vulnerable to the vector of weights (Cotter \& Longin, 2011), we consider equally weighted portfolios. We used the GARCH (Bollerslev, 1986), exponential GARCH (Nelson, 1991), GJR-GARCH (Glosten et al.,1993) and GARCH-Filtered Historical
Simulation-based approaches (Barone-Adesi et al., 1998; Hull \& White, 1998) to calculate volatility and Value at Risk for stock and commodity portfolios and their constituents. In practice the most commonly used model for estimating volatility of financial instruments and commodities is GARCH(1,1) (Bollerslev, 1986):

$$
r_{t}=\sigma_{t} \varepsilon_{t}, \sigma_{t}^{2}=\omega+\alpha r_{t-1}^{2}+\beta \sigma_{t-1}^{2},
$$

where: $\omega, \alpha, \beta>0, \alpha+\beta<1, \varepsilon_{t} \sim \operatorname{iid}(0,1), r_{t}$ returns in period $t, \sigma_{t}^{2}-$ conditional volatility (variance) in time $t$. This model takes into account the conditional heteroscedasticity of returns. Although it is relatively simple, it provides relatively good estimates and forecasts of volatility compared to much more complex models. However, for some series of returns, models that take into account a leverage effect are better than the $\operatorname{GARCH}(1,1)$ model (see e.g. Hansen \& Lunde, 2005). 
The exponential GARCH(1,1), i.e. EGARCH( $(1,1)$ model of Nelson models the asymmetric impact of negative and positive returns on the conditional volatility (Nelson, 1991):

$$
\underset{\beta \log \sigma_{t-1}^{2},}{\log \sigma_{t}^{2}=\omega+\alpha \varepsilon_{t-1}+\gamma\left(\left|\varepsilon_{t-1}\right|-E\left(\left|\varepsilon_{t-1}\right|\right)\right)+}
$$

where: $\alpha$ captures the sign effect and $\gamma-$ the size effect. This model captures the stylised fact that volatility reacts asymmetrically to the good and bad news.

Another model that takes into account the asymmetry is the GJR-GARCH(1,1) model (Glosten et al., 1993):

$$
\sigma_{t}^{2}=\omega+\alpha r_{t-1}^{2}+\gamma I\left(r_{t-1}<0\right) r_{t-1}^{2}+\beta \sigma_{t-1}^{2}
$$

where: $\gamma$ now represents the leverage term, $I$ takes value 1 for $r_{t-1}<0$ and 0 otherwise. This model captures the well-known property that negative shocks at $t-1$ time have a stronger impact in the volatility at time $t$ than positive ones. This asymmetry is called the leverage effect.

Because a strong ARCH effect was experienced even with a one-day lag for the returns of stock sectors and the returns of commodity sectors (Table 1 ), the $\operatorname{GARCH}(1,1)$ model with normal distributed innovations was estimated for the returns (approach I). To capture the asymmetric impact of positive and negative returns on the conditional volatility, the models: $\operatorname{EGARCH}(1,1)$ and GJR-GARCH$(1,1)$ with normally distributed innovations were also estimated. We used the rugarch package in the R and G@RCH package in OxMetrics7. The choice of the best model from the GARCH, EGARCH and GJR-GARCH models was made on the basis of information criteria and properties of model residues (approach II). To capture the long memory effect in volatility we tried to use the FIGARCH model as well in approach II. The problem of no convergence disabled us to use this model in our calculations. The correct estimates of VaR for stocks portfolio (see e.g. Angelidis et al., 2007), energy commodities (see e.g. Marimoutou et al., 2009; Cheng \& Hung, 2011), metals (see e.g. Cheng \& Hung, 2011) and agricultural commodities (see e.g. Just, 2014) may be obtained from the GARCH-Filtered Historical Simulation model (GARCHFHS). This model uses the historical simulation method for standardized residuals of the GARCH model (Barone-Adesi et al., 1999):

$$
q_{\alpha}=\sigma_{t}(1) F_{\varepsilon_{t}}^{-1}(\alpha)
$$

where: $\sigma_{t}(1)-$ a one-period-ahead forecast of conditional volatility of the GARCH model, $F_{\varepsilon_{t}}^{-1}(\alpha)-\alpha$ empirical quantile of standardised residuals of the GARCH model. VaR was computed for long and short positions and for the confidence levels of $0.90,0.95$ and 0.99 , respectively. Then the correlation indices implied from volatility and $\mathrm{VaR}$ were determined for the stock and commodity sectors.

Figure 3 shows the daily implied correlation indices for the stock and commodity sectors. Figure 4, in turn, shows the daily implied correlation index and daily VaR-implied correlation indices for portfolios of all stocks and all commodities. No differences were found in both approaches. We performed the Wilcoxon rank sum test indicating no differences at the significance level of 0.05 . The correlation indices appear to be highly volatile over the examined period. In periods of high volatility the implied correlation indices are higher than the average pair-wise Pearson correlation. In periods of low volatility the result is opposite. The increase in correlations in 2008 and 2012, when the global economy was in decline, were evident. This finding is in line with many studies, e.g. Solnik et al. (1996), Longin and Solnik (2001), Ang and Chen (2002), Sandoval Jr. and Franca (2012). In the commodity futures market the highest values of correlation were estimated for metals and the lowest for agricultural commodities. Although metals are permanently highly dependent, the correlation chart behaves differently than for the other sectors. It does not have the peaks in the times of crisis, because precious metals become a safe haven for investors in those times. In the case of the stock market the highest values of correlation were estimated for the financial sector. Both sectors, i.e. metals and financials, are perceived as more homogeneous than others. The financial sector was the one most affected during the credit crunch of 2007-2009, but a very high correlation, similarly to metals, persisted throughout the entire period analysed in our study. Wanat et al. (2015) also found a high level of the conditional correlation between precious metals in the period of 2004-2013. In the entire period, except for October 2008-January 2009, the values of the correlation index for the commodity portfolio indicate a weak or very weak dependence. Because most sectors behave similarly, we checked the level of similarity between the implied correlation indices using Kendall's tau coefficient. The highest tau is obtained between the implied correlation indices for the technology-industrials and basic materials-industrials. Such a result suggests a close relationship between firms operating in the three sectors of economy. For the sake of brevity the results are not presented here ${ }^{1}$.

VaR-correlation estimates for the confidence level of 0.9 for long and short positions are higher than the correlation index estimates (at the significance level of 0.05 , the Wilcoxon rank sum test). The exceptions are metals (left tail) and commodities (right tail). Moreover, the VaRimplied correlation estimates for long and short positions are different (at the significance level of 0.05, the Wilcoxon rank sum test). Usually the correlation in the left tail is higher than in the right tail (at the significance level of 0.05 , Wilcoxon rank sum test). This means that when the stock or commodity market plunges, the correlation between assets increases more markedly than during rise of the market. Our results are in line with most of precious studies in financial markets (see e.g. Longin \& Solnik, 2001; Ang \& Chen, 2002; Cotter \& Longin, 2011). It should be mentioned that Attaf et al. (2015), in contrast to these results, showed that non-energy commodity spot prices are more likely to move together during bull markets than in bear markets (19602014).

\footnotetext{
${ }^{1}$ Results of calculations are available from the authors' upon request.
} 

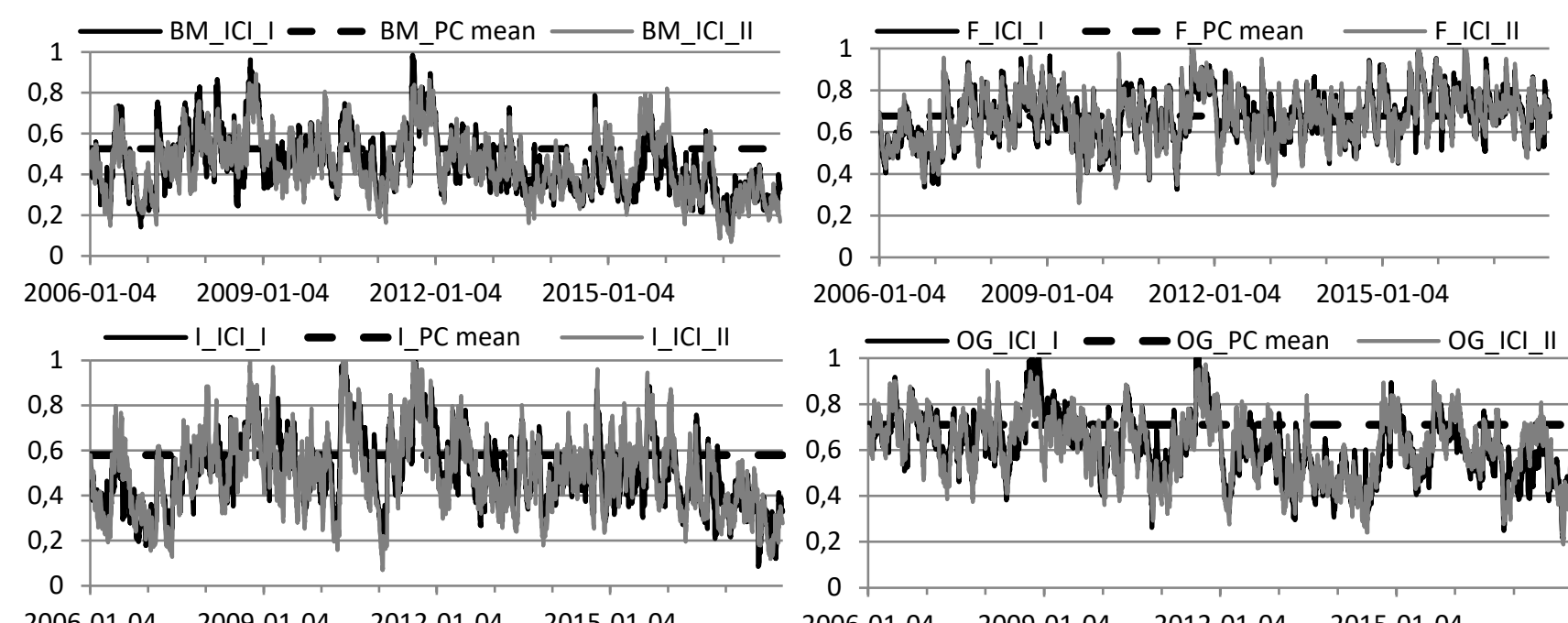

2006-01-04 2009-01-04 2012-01-04 2015-01-04
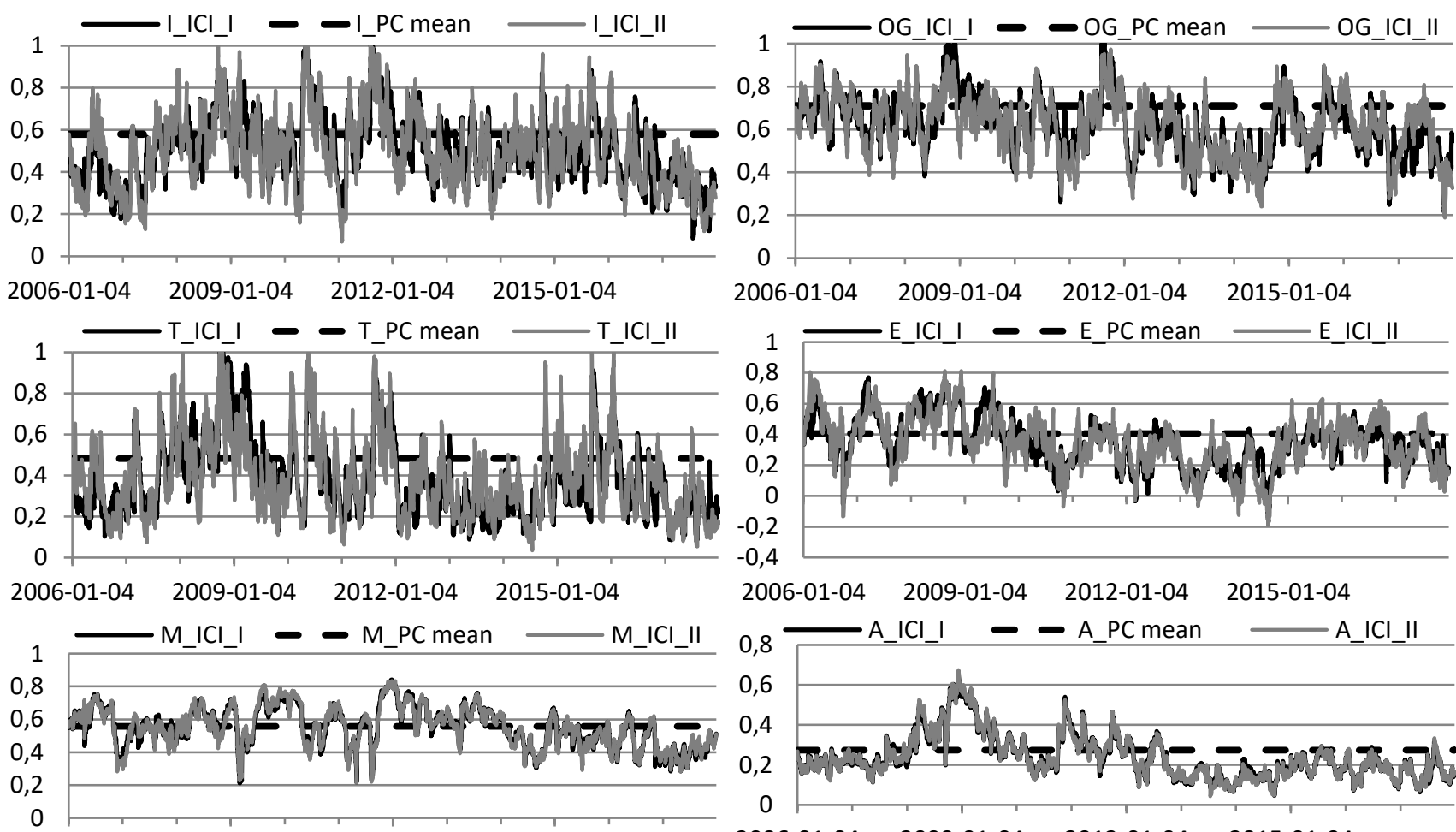

2009-01-04 2012-01-04 2015-01-04

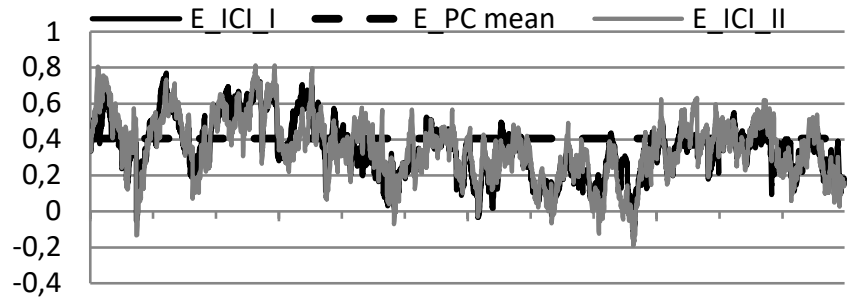

2006-01-04 2009-01-04 2012-01-04 2015-01-04

2006-01-04 2009-01-04 2012-01-04 2015-01-04

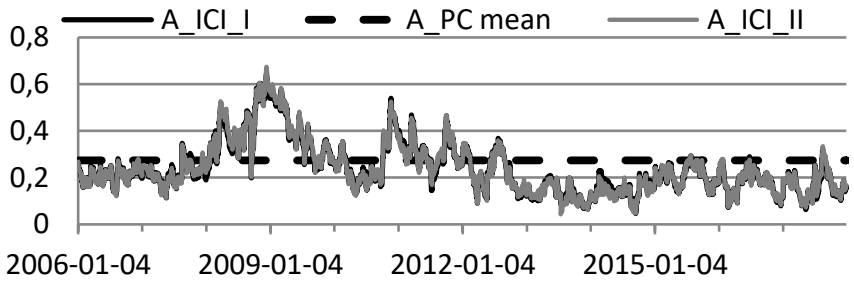

Note: BM-basic materials, $F$-financial, I-industrials, $O G$ - oil \& gas, $T$-technology, E-energy, $M$ - metals, $A$-agriculture sectors, $P C$ - Pearson coefficient for returns,_I-approach I,_II-approach II.

Figure 3. Daily ICI for Stock and Commodity Sectors
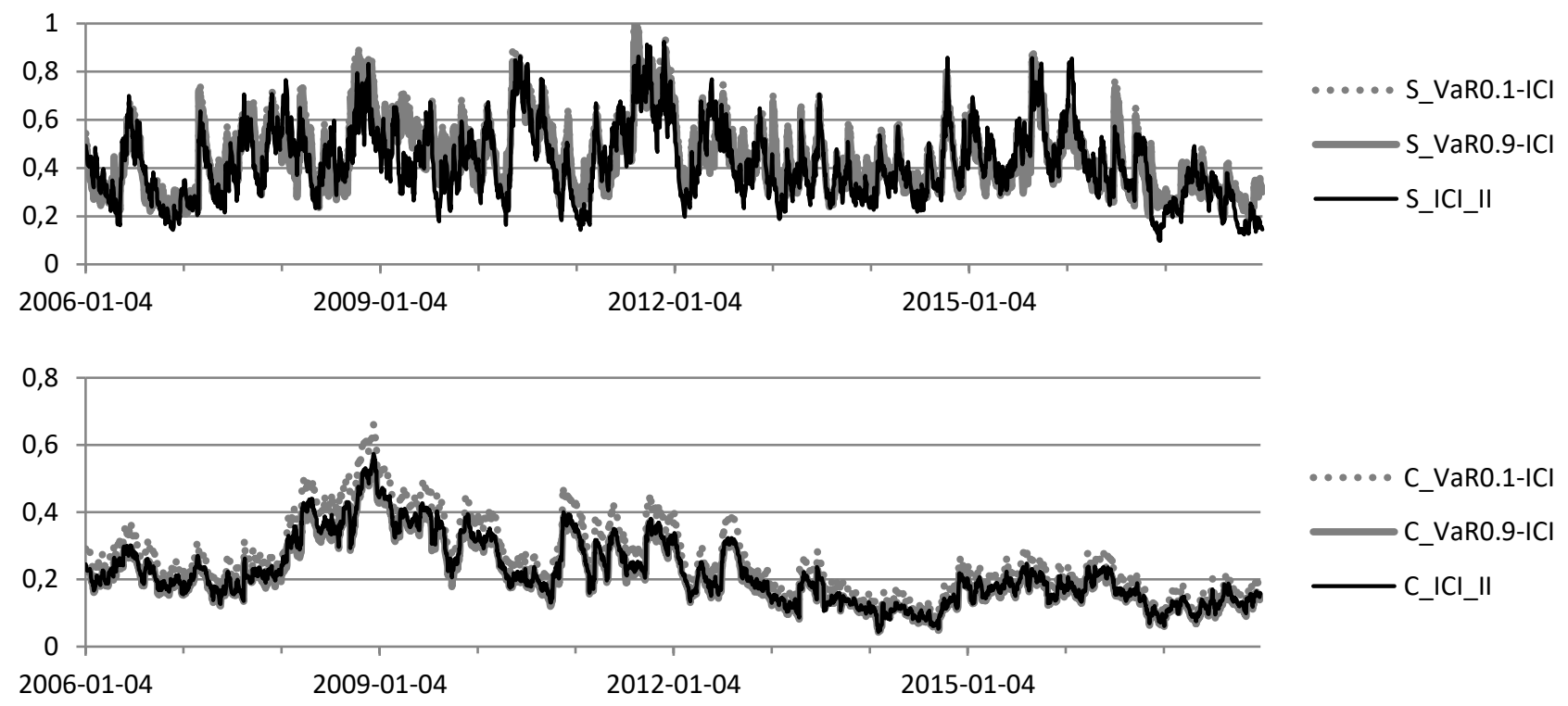

Note: $S$ - portfolio of all stocks, $C$ - portfolio of all commodities, _II-approach II.

Figure 4. Daily ICI and VaR-ICI (for confidence level of 0.9) for the Portfolio of all Stocks and the Portfolio of all Commodities 


\section{Stylised Facts about Correlation}

In this section we focus on the most important features of the correlation estimates within the considered sectors of the stock and commodity futures markets. The facts were considered in literature for pair-wise correlations and option-implied correlations, but to date not for the implied correlations.

\section{Correlation Long Memory}

Clustering in correlation implies that periods of high correlation in the market are likely to be followed by periods of high correlation, while periods of low correlation are likely to be followed by periods of low correlation. The reason is that the length of the investment horizon and the level of portfolio diversification determine the risk of portfolio and cause differences in the rate of reaction to market changes. This phenomenon is proved by the slowly decaying autocorrelation function. Figure 5 shows the autocorrelation functions for the daily implied correlation indices for the stock and commodity sectors. A significant autocorrelation indicates long memory (persistence) in the correlation values between the considered assets. Although the strongest dependencies in the correlation indices are observed for the number of lags corresponding to several months, even for the more and more distant lags, the autocorrelation in the implied correlation indices is statistically significant. In addition, the effect of long memory in the implied correlation is stronger in commodity sectors. Similar results for the implied correlation index from the DJIA index option prices - DJCIX (October 2001October 2002) were presented by Skintzi and Refenes (2005). Andersen et al. (2001) also obtained similar results for the realised correlations for the DJIA stocks (19931998). In our study we calculated autocorrelation for each ICI and for their first differences. The results of our computations for the first five lags are presented in Table 2. They confirmed the existence of long memory in correlation for all the considered sectors. This means that when a market experiences high correlations, especially during downturns, a high dependence between assets should be expected. Assets in portfolios behave similarly and portfolios become riskier for a long time. When we focus on changes of ICI we find a big difference between stocks and commodities. The daily changes of ICI for the stock sectors are correlated with its values lagged by one day, but there is no such evidence for commodities. The Ljung-Box test statistic does not reject the hypothesis of zero autocorrelations for changes in the commodity ICI.

Table 2

Autocorrelations for Daily ICI and Changes of ICI

\begin{tabular}{|c|c|c|c|c|c|c|c|c|c|c|}
\hline \multirow{3}{*}{ Sector } & \multicolumn{5}{|c|}{ ICI } & \multicolumn{5}{|c|}{ Changes of ICI } \\
\hline & ACF lag 1 & ACF lag 2 & ACF lag 3 & ACF lag 4 & ACF lag 5 & ACF lag 1 & ACF lag 2 & ACF lag 3 & ACF lag 4 & ACF lag 5 \\
\hline & \multicolumn{10}{|c|}{ Approach I } \\
\hline Basic materials & $0.96 * * *$ & $0.93 * * *$ & $0.90 * * *$ & $0.87 * * *$ & $0.84 * * *$ & $-0.05 * * *$ & -0.02 & -0.02 & -0.01 & -0.02 \\
\hline Financials & $0.93 * * *$ & $0.88 * * *$ & $0.82 * * *$ & $0.77 * * *$ & $0.72 * * *$ & $-0.09 * * *$ & 0.02 & $-0.04 * *$ & -0.01 & $-0.04 * *$ \\
\hline Industrials & $0.97 * * *$ & $0.94 * * *$ & $0.91 * * *$ & $0.88 * * *$ & $0.85 * * *$ & $-0.07 * * *$ & 0.01 & -0.01 & 0.01 & -0.02 \\
\hline Oil \& gas & $0.97 * * *$ & $0.94 * * *$ & $0.91 * * *$ & $0.89 * * *$ & $0.86 * * *$ & $-0.08 * * *$ & 0.01 & $-0.03 *$ & $-0.04 * *$ & -0.01 \\
\hline Technology & $0.98 * * *$ & $0.95 * * *$ & $0.93 * * *$ & $0.91 * * *$ & $0.88 * * *$ & $-0.04 * *$ & 0.01 & $0.03 *$ & 0.02 & -0.03 \\
\hline Stocks & $0.96^{* * *}$ & $0.93 * * *$ & $0.90 * * *$ & $0.87 * * *$ & $0.84 * * *$ & $-0.08 * * *$ & 0.02 & -0.02 & 0.00 & $-0.03 *$ \\
\hline Energy & $0.98 * * *$ & $0.96 * * *$ & $0.94 * * *$ & $0.92 * * *$ & $0.91 * * *$ & 0.01 & -0.03 & -0.02 & -0.01 & 0.01 \\
\hline Metals & $0.99 * * *$ & $0.97 * * *$ & $0.96 * * *$ & $0.94 * * *$ & $0.92 * * *$ & 0.02 & 0.01 & 0.01 & 0.02 & 0.02 \\
\hline Agriculture & $0.99 * * *$ & $0.98 * * *$ & $0.97 * * *$ & $0.95 * * *$ & $0.94 * * *$ & 0.01 & -0.01 & -0.02 & 0.01 & -0.01 \\
\hline Commodities & $0.99 * * *$ & $0.99 * * *$ & $0.98 * * *$ & $0.97 * * *$ & $0.96 * * *$ & 0.00 & 0.00 & 0.00 & $0.04 * *$ & -0.01 \\
\hline Sector & \multicolumn{10}{|c|}{ Approach II } \\
\hline Basic materials & $0.97 * * *$ & $0.94 * * *$ & $0.91 * * *$ & $0.88 * * *$ & $0.85 * * *$ & $-0.03 *$ & 0.00 & 0.00 & -0.02 & -0.03 \\
\hline Financials & $0.94 * * *$ & $0.89^{* * *}$ & $0.83 * * *$ & $0.78 * * *$ & $0.74 * * *$ & $-0.08 * * *$ & 0,02 & $-0.05 * * *$ & 0,00 & $-0.04 * *$ \\
\hline Industrials & $0.96 * * *$ & $0.92 * * *$ & $0.89 * * *$ & $0.85 * * *$ & $0.81 * * *$ & -0.03 & -0.02 & -0.01 & 0.02 & $-0.06 * * *$ \\
\hline Oil \& gas & $0.96 * * *$ & $0.93 * * *$ & 0.90 *** & $0.87 * * *$ & $0.84 * * *$ & $-0.04 * *$ & -0.02 & -0.03 & -0.02 & -0.03 \\
\hline Technology & $0.96 * * *$ & $0.92 * * *$ & $0.88 * * *$ & $0.84 * * *$ & $0.81 * * *$ & $-0.05 * * *$ & 0.01 & -0.02 & 0.01 & $-0.04 * *$ \\
\hline Stocks & $0.96 * * *$ & $0.93 * * *$ & 0.90 *** & 0.87 *** & $0.83 * * *$ & $-0.04 * *$ & 0.01 & 0.00 & 0.00 & $-0.06 * * *$ \\
\hline Energy & $0.97 * * *$ & $0.94 * * *$ & $0.92 * * *$ & $0.89 * * *$ & $0.87 * * *$ & -0.01 & -0.02 & $-0.05 * * *$ & -0.02 & 0.01 \\
\hline Metals & $0.98 * * *$ & $0.97 * * *$ & $0.95 * * *$ & $0.94 * * *$ & $0.92 * * *$ & 0.01 & 0.01 & 0.00 & 0.01 & 0.02 \\
\hline Agriculture & $0.99^{* * *}$ & $0.98^{* * *}$ & $0.97 * * *$ & $0.96^{* * *}$ & $0.95^{* * *}$ & 0.00 & -0.01 & -0.02 & 0.01 & -0.02 \\
\hline Commodities & $0.99 * * *$ & $0.99 * * *$ & $0.98 * * *$ & $0.97 * * *$ & $0.96 * * *$ & -0.01 & 0.00 & 0.00 & $0.03 *$ & -0.01 \\
\hline
\end{tabular}






Note: BM-basic materials, $F$-financial, I-industrials, OG-oil \& gas, $T$-technology, E-energy, $M$ - metals, A-agriculture sectors, $S$ - portfolio of all stocks, $C$ - portfolio of all commodities.

Figure 5. Autocorrelations of Daily ICI up to 250 Lags (approach II)

\section{Asymmetry in Correlation}

Asymmetry in correlation means that negative returns have a greater impact on the today's or future dependence than positive returns of the same value. The phenomenon is documented for pair-wise correlations and option-implied correlations. Andersen et al. (2001) found a weak asymmetry in the relationship between the realised correlations for the DJIA stocks (1993-1998) and past returns. In turn, Ang and Chen (2002) and Longin and Solnik (2001) documented asymmetry in upside and downside correlations between stocks and portfolios. They concluded that stocks and their portfolios are much more likely to move together with the market when the market is shrinking. Skintzi and Refenes (2005) also found greater correlations between equity portfolios and the aggregate market in downside markets than in upside markets. Table 3 presents correlation coefficients for the daily ICI changes and one-day lagged returns (all returns, absolute returns, positive returns, negative returns) for the stock and commodity sectors. The correlation coefficients for changes of ICI and lagged returns are significantly negative for all portfolios. Moreover, the dependence is much higher when asymmetric GARCH models are used to estimate volatility. We also found a significant positive correlation for changes of ICI and lagged absolute returns. The correlation coefficients for ICI changes and lagged negative returns are significantly negative for all the considered sectors, and much higher for the stock and energy sectors for approach II. For positive returns the result is ambiguous, especially when the asymmetric GARCH models are used. The magnitude of Pearson coefficients is greater for negative returns than for positive ones. This result indicates that negative returns have a greater impact on future average correlations in portfolios than positive returns of the same absolute magnitude. Therefore negative returns have a high explanatory power in forecasting the behaviour of future portfolios.

Table 3

Pearson Coefficients for Daily ICI Changes and One-Day Lagged Returns

\begin{tabular}{|c|c|c|c|c|c|c|c|c|c|c|c|}
\hline Sector & Basic materials & Financials & Industrials & Oil \& gas & Technology & Stocks & Energy & Metals & Agriculture & Commodities \\
\hline Returns R & \multicolumn{9}{|c|}{ Approach I } \\
\hline All R & $-0.11^{* * *}$ & $-0.04^{* *}$ & $-0.10^{* * *}$ & $-0.12^{* * *}$ & $-0.05^{* *}$ & $-0.14^{* * *}$ & $-0.10^{* * *}$ & $-0.05^{* *}$ & $-0.06^{* *}$ & $-0.06^{* *}$ \\
\hline Absolute R & $0.62^{* * *}$ & $0.49^{* * *}$ & $0.59^{* * *}$ & $0.57^{* * *}$ & $0.62^{* * *}$ & $0.62^{* * *}$ & $0.18^{* * *}$ & $0.38^{* * *}$ & $0.68^{* * *}$ & $0.62^{* * *}$ \\
\hline Negative R & $-0.44^{* * *}$ & $-0.34^{* * *}$ & $-0.42^{* * *}$ & $-0.41^{* * *}$ & $-0.41^{* * *}$ & $-0.47^{* * *}$ & $-0.18^{* * *}$ & $-0.24^{* * *}$ & $-0.42^{* * *}$ & $-0.39^{* * *}$ \\
\hline Positive R & $0.29^{* * *}$ & $0.27^{* * *}$ & $0.28^{* * *}$ & $0.26^{* * *}$ & $0.33^{* * *}$ & $0.28^{* * *}$ & 0.02 & $0.19^{* * *}$ & $0.34^{* * *}$ & $0.32^{* * *}$ \\
\hline Returns R & \multicolumn{9}{|c|}{ Approach II } \\
\hline All R & $-0.80^{* * *}$ & $-0.21^{* * *}$ & $-0.78^{* * *}$ & $-0.66^{* * *}$ & $-0.73^{* * *}$ & $-0.81^{* * *}$ & $-0.37^{* * *}$ & $0.15^{* * *}$ & $-0.06^{* *}$ & 0.01 \\
\hline Absolute R & $0.25^{* * *}$ & $0.42^{* * *}$ & $0.28^{* * *}$ & $0.39^{* * *}$ & $0.39^{* * *}$ & $0.21^{* * *}$ & $0.13^{* * *}$ & $0.37^{* * *}$ & $0.67^{* * *}$ & $0.62^{* * *}$ \\
\hline Negative R & $-0.77^{* * *}$ & $-0.43^{* * *}$ & $-0.76^{* * *}$ & $-0.73^{* * *}$ & $-0.82^{* * *}$ & $-0.74^{* * *}$ & $-0.38^{* * *}$ & $-0.08^{* * *}$ & $-0.41^{* * *}$ & $-0.33^{* * *}$ \\
\hline Positive R & $-0.52^{* * *}$ & $0.11^{* * *}$ & $-0.48^{* * *}$ & $-0.31^{* * *}$ & $-0.36^{* * *}$ & $-0.54^{* * *}$ & $-0.24^{* * *}$ & $0.36^{* * *}$ & $0.33^{* * *}$ & $0.37^{* * *}$ \\
\hline
\end{tabular}

\section{Correlation and Volatility Co-Movement}

The positive relationship between correlation and volatility was already shown at the beginning of this section. It is evident in Figures 3 and 4 that markets become more correlated in more volatile environments. This phenomenon has been considered by many authors, e.g. Solnik et al.,
(1996), Ramchand and Susmel (1998), Ang and Chen (2002), Skintzi and Refenes (2005) and Bartram and Wang (2005). The correlation coefficients of daily ICI changes and portfolio volatility changes for the stock and commodity sectors are presented in Table 4 . This shows strong positive relationships for stocks (0.82) and for commodities $(0.75)$ between the implied correlations and portfolio volatilities. 
The only exception is the energy sector with a weak, but significant correlation of 0.26 . The nature of the relationship between correlation and volatility is evident in Figure 6, which presents a scatterplot of the daily changes of ICI against the daily changes of volatility for the entire stock and commodity portfolios.

A Granger causality (Granger, 1969) is a concept, which allow us to distinguish the driver variable from the recipient. The Granger causality test considers a bivariate autoregressive model of two variables $X$ and $Y$ (Osinska, 2008):

$$
\begin{aligned}
& y_{t}=\alpha_{0}+\sum_{i=1}^{p} \alpha_{i} y_{t-i}+\sum_{i=1}^{p} \beta_{i} x_{t-i}+\eta_{t}, \\
& y_{t}=\alpha_{0}+\sum_{i=1}^{p} \alpha_{i} y_{t-i}+\varepsilon_{t} .
\end{aligned}
$$

where $p$ is the maximum number of lagged observations included in the considerations. The null hypothesis $H_{0}$ for the test is that lagged $X$-values do not explain the variation in $Y\left(\beta_{i}=0, i=1, \ldots, p\right)$ against $H_{1}: X$ is the Granger cause for $Y\left(\beta_{i} \neq 0\right)$. The Fisher-Snedecor test statistic is defined as (Osinska, 2008):

$$
F=\frac{\left(s^{2}\left(\varepsilon_{t}\right)-S^{2}\left(\eta_{t}\right)\right) / p}{S^{2}\left(\eta_{t}\right) /(T-2 p-1)}
$$

where: $T$ is a sample size and $S^{2}$ are two sums of squared residuals related to the restricted (9) and unrestricted (10) form of the equation. The test statistic $F$ has the FisherSnedecor distribution with the $p$ and $T-2 p-1$ degrees of freedom when the null hypothesis is true.

In our study we used the Granger causality test in order to test whether ICI changes affect portfolio volatility changes or inversely, if portfolio volatility changes affect ICI changes. The results of calculations for 5 lags are presented in Table 5. It may be argued at the significance level of 0.1 past values of the implied correlation contribute to the prediction of the present value of volatility even with past values of volatility. The only exception is found for the basic materials portfolio in approach II. However, an opposite effect (volatility is a Granger cause for the implied correlation) holds approximately for half of all cases. Our results for the Granger test causality confirm that the implied correlations are a key driver of stock market volatility. This conclusion is in line with a study of Skintzi and Refenes (2005), who concluded that while changes in the stock market volatility do not affect future changes in the level of stock return correlations, changes in the level of stock return correlations appear to cause future stock market volatility changes.

Table 4

Pearson Coefficient for Daily ICI and Volatility Changes

\begin{tabular}{|c|c|c|c|c|c|c|c|c|c|c|}
\hline Approach & Basic materials & $\begin{array}{c}\text { Financial } \\
\mathbf{s}\end{array}$ & Industrials & Oil \& gas & Technology & Stocks & Energy & Metals & Agriculture & Commodities \\
\hline I & $0.83^{* * *}$ & $0.66^{* * *}$ & $0.78^{* * *}$ & $0.73^{* * *}$ & $0.77^{* * *}$ & $0.83^{* * *}$ & $0.19^{* * *}$ & $0.44^{* * * *}$ & $0.77^{* * *}$ & $0.76^{* * *}$ \\
\hline II & $0.83^{* * *}$ & $0.63^{* * *}$ & $0.83^{* * *}$ & $0.77^{* * *}$ & $0.89^{* * *}$ & $0.82^{* * *}$ & $0.26^{* * *}$ & $0.42^{* * * *}$ & $0.75^{* * *}$ & $0.75^{* * *}$ \\
\hline
\end{tabular}

Note: *** indicates significance at 0.01 .

\begin{tabular}{|c|c|c|c|c|}
\hline \multirow{2}{*}{ Hypothesis tested } & \multicolumn{2}{|c|}{ Approach I } & \multicolumn{2}{|c|}{ Approach II } \\
\hline & F-statistic & $p$-values & F-statistic & $p$-values \\
\hline$\sim$ Basic materials ICI changes $\rightarrow$ Volatility changes & 5.15 & 0.000 & 1.68 & 0.137 \\
\hline$\sim$ Volatility changes $\rightarrow$ Basic materials ICI changes & 1.88 & 0.095 & 1.34 & 0.244 \\
\hline$\sim$ Financials ICI changes $\rightarrow$ Volatility changes & 4.04 & 0.001 & 2.25 & 0.047 \\
\hline$\sim$ Volatility changes $\rightarrow$ Financials ICI changes & 1.19 & 0.309 & 0.49 & 0.786 \\
\hline$\sim$ Industrials ICI changes $\rightarrow$ Volatility changes & 3.18 & 0.007 & 2.11 & 0.061 \\
\hline$\sim$ Volatility changes $\rightarrow$ Industrials ICI changes & 4.29 & 0.001 & 3.85 & 0.002 \\
\hline$\sim$ Oil \& gas ICI changes $\rightarrow$ Volatility changes & 3.64 & 0.003 & 1.90 & 0.090 \\
\hline$\sim$ Volatility changes $\rightarrow$ Oil \& gas ICI changes & 0.93 & 0.457 & 2.53 & 0.027 \\
\hline$\sim$ Technology ICI changes $\rightarrow$ Volatility changes & 3.11 & 0.008 & 6.41 & 0.000 \\
\hline$\sim$ Volatility changes $\rightarrow$ Technology ICI changes & 1.80 & 0.109 & 4.81 & 0.000 \\
\hline$\sim$ Stocks ICI changes $\rightarrow$ Volatility changes & 2.30 & 0.043 & 2.59 & 0.024 \\
\hline$\sim$ Volatility changes $\rightarrow$ Stocks ICI changes & 2.93 & 0.012 & 5.86 & 0.000 \\
\hline$\sim$ Energy ICI changes $\rightarrow$ Volatility changes & 2.21 & 0.051 & 2.06 & 0.068 \\
\hline$\sim$ Volatility changes $\rightarrow$ Energy ICI changes & 1.40 & 0.220 & 1.53 & 0.177 \\
\hline$\sim$ Metals ICI changes $\rightarrow$ Volatility changes & 2.75 & 0.018 & 3.82 & 0.002 \\
\hline$\sim$ Volatility changes $\rightarrow$ Metals ICI changes & 1.19 & 0.312 & 0.81 & 0.541 \\
\hline$\sim$ Agriculture ICI changes $\rightarrow$ Volatility changes & 3.26 & 0.006 & 3.45 & 0.004 \\
\hline$\sim$ Volatility changes $\rightarrow$ Agriculture ICI changes & 5.01 & 0.000 & 4.81 & 0.000 \\
\hline$\sim$ Commodities ICI changes $\rightarrow$ Volatility changes & 3.85 & 0.002 & 3.63 & 0.003 \\
\hline$\sim$ Volatility changes $\rightarrow$ Commodities ICI changes & 3.12 & 0.008 & 2.71 & 0.019 \\
\hline
\end{tabular}

Results for the Granger Causality Test for Daily ICI and Volatility Changes for 5 Lags 
Stocks

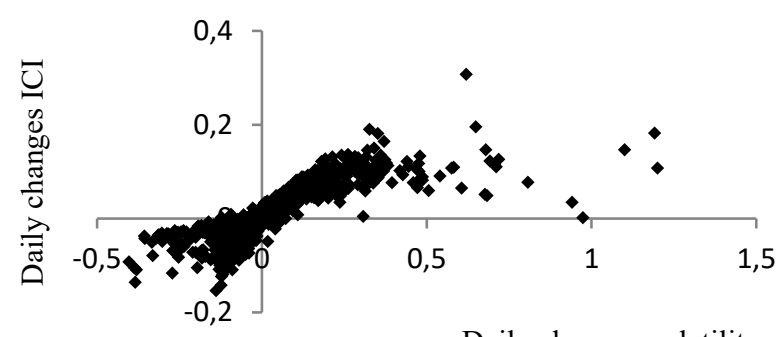

Commodities

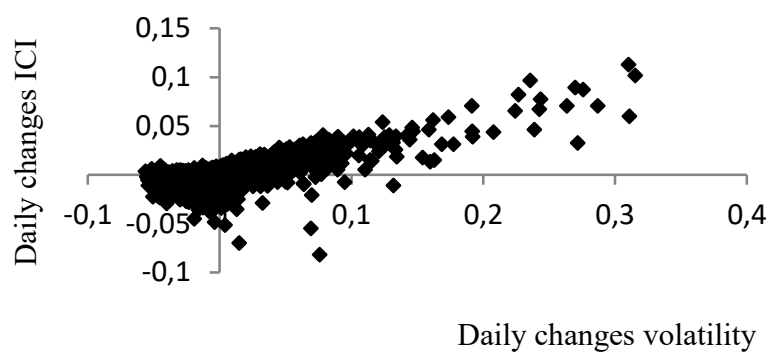

Figure 6. A Scatterplot of Daily Changes of ICI against Daily Changes of Volatility for Stock and Commodity Portfolios (Approach II)

\section{Conclusions}

The implied correlation index (ICI) is a useful measure to describe the dependence structure of a portfolio. An advantage of ICI is that only one number may describe the average dependence between assets in the portfolio. Additionally, contrary to the option-implied correlation, the ICI may be derived for any portfolio. The paper empirically examines the time-varying implied correlation for various commodity (metals, energy, agriculture) and stock (basic materials, financials, industrials, oil \& gas, technology) sectors. The daily data from 2006 to 2017 are used in the research. We selected a relatively long period of time in order to explore the pattern and behaviour of implied correlations in the specified portfolios for various states of the market. The findings of the paper are several. We proposed to apply the GARCH-based approaches to capture the dynamic character of volatility and finally the dynamic character of the implied correlation. We used the basic $\operatorname{GARCH}(1,1)$ and other types of GARCH family models to check the robustness of our results to the choice of the model. We did not observe significant differences in the estimation of the implied correlation indices for both approaches. Stock portfolios indicate a greater dependence and greater dynamics than commodity portfolios. Assets in all sectors tend to be more dependent in times of high volatility. In these periods investors should reduce stock positions more than commodity positions. The most dependent sectors within the stock and commodity sectors are financials and metals, respectively. The agricultural sector is the less correlated sector.

We examined four stylised facts concerning the correlation with reference to implied correlation indices. The findings of this study have strong practical implications for investors, fund managers and regulators. Knowledge concerning the properties may be necessary for valid risk aggregation, valuation of the investment portfolio and effective portfolio management. The implied correlation clustering is the first property of the implied correlation. It shows that assets respond to new information with large price co-movement, and this high dependency tends to last for a while after the initial shock. The risk of a portfolio rises as a consequence of increasing correlation. We found longterm memory in the implied correlation for all the considered portfolios. In addition, the effect of long memory in the implied correlation was stronger in the commodity sectors. This may be related to various groups of investors on the commodity futures market (non-commercial, commercial and index traders), who take different positions (long, short) to speculate or to hedge their risk exposure. The effect of long memory means that an increase in correlation between assets increases the systematic risk of the market or sector and the risk tends to be maintained for a long time. Such a finding reveals a substantial reduction in the benefits of diversification when the implied correlation of portfolio rises. Investors ought to find then distinct instruments to hedge their portfolios against large price movements. Implied correlation indices demonstrate a strong asymmetry. Vulnerability to the past negative returns is greater than in relation to the positive returns. The property holds especially for stock portfolios. This means that negative returns should make investors more inclined to look at their portfolios as a whole rather than a set of individual assets. The usage of hedging strategy using derivatives should be considered in such circumstances. The last investigated property is volatility and correlation comovement. We found a strong co-movement level for almost all the considered portfolios. We conducted the Granger causality test to explain what type of dependence exists between volatility and the implied correlation, i.e. which variable is the cause and has the driving (causative) force, and which is the effect. For most portfolios the implied correlation appears to cause market volatility. The property might be used to find the explanatory power of implied correlation indices in predicting future volatility.

Correlations between assets change significantly, causing many difficulties in building well diversified portfolios. Using one value to each pair-wise correlation instead of their real values, investors may build more stable portfolios. Elton and Gruber (1973) and Ledoit and Wolf (2003) showed that the application of an average correlation facilitates the selection of a portfolio with a lower volatility compared to portfolios based on pair-wise correlations. Analysis of the diversification effect in the case for dynamic version of the implied correlation will be considered in our future work. We are also going to extend the research for other markets and portfolios. The results presented in the paper focus on American commodity futures and stock markets, which are perceived as global markets. It would be interesting to compare dynamics and properties of the implied correlations for portfolios built in developed and emerging financial markets. 


\section{Acknowledgements}

We acknowledge the constructive feedback on the earlier versions of this paper from the participants at the 61st Meeting of EURO Working Group for Commodities and Financial Modelling, Kaunas University of Technology, 2018. The authors are very grateful for the insightful and beneficial comments received from two anonymous Reviewers. Any remaining errors are the responsibility of the authors alone.

\section{References}

Andersen, T. G. (1996). Return Volatility and Trading Volume: An Information Flow Interpretation of Stochastic Volatility. Journal of Finance, 51(1), 169-204. https://doi.org/10.1111/j.1540-6261.1996.tb05206.x

Andersen, T. G., Bollerslev, T., \& Cai, J. (2000). Intraday and Interday Volatility in the Japanese Stock Market. Journal of International Financial Markets, Institutions and Money, 10(2), 107-130. http://dx.doi.org/10.1016/S10424431(99) 00029-3

Andersen, T. G., Bollerslev, T., Diebold, F. X., \& Ebens, H. (2001). The distribution of realized stock return volatility. Journal of Financial Economics, 61(1), 43-76. https://doi.org/10.1016/S0304-405X(01)00055-1

Andersen, T. G., Bollerslev, T., Diebold, F. X., \& Labys, P. (1999). Realized Volatility and Correlation. Manuscript, Northwestern University, Duke University and University of Pennsylvania. Available from: https://www.sas.upenn. edu/ fdiebold/papers/paper29/temp.pdf.

Ang, C., \& Chen, J. (2002). Asymmetric correlations of equity portfolios. Journal of Financial Economics, 63(3), 443494. https://doi.org/10.1016/S0304-405X(02)00068-5

Angelidis, T., Benos, A., \& Degiannakis, S. (2007). A Robust VaR Model under Different Time Periods and Weighting Schemes. Review of Quantitative Finance and Accounting, 2(28), 187-201. https://doi.org/10.1007/s11156-006-0010-y

Attaf, Z., Ghorbel, A., \& Boujelbène, Y. (2015). Dependence between Non-Energy Commodity Sectors Using Time-Varying Extreme Value Copula Methods. International Journal of Econometrics and Financial Management, 3(2), 64-75. https://doi.org/10.12691/ijefm-3-2-3.

Barone-Adesi, G., Bourgoin, F., \& Giannopoulos, K. (1998). Don't Look Back. Risk, 11, 100-104.

Barone-Adesi G., Giannopoulos, K., \& Vosper, L. (1999). VaR without correlations for portfolios of derivative securities. Journal of Futures Markets, 19(5), 583-602. https://doi.org/10.1002/(SICI)1096-9934(199908)19:5<583::AIDFUT5>3.0.CO;2-S

Bartram, S.M. \& Wang, Y. H. (2005), Another look at the relationship between cross-market correlation and volatility, Finance Research Letters, 2 (2), 75-88. https://doi.org/10.1016/j.frl.2005.01.002

Bauwens, L., Laurent, S., \& Rombouts, J. V. K. (2006). Multivariate GARCH models: a survey. Journal of Applied Econometrics, 21(1), 79-109. https://doi.org/10.1002/jae.842

Bollerslev, T. (1986). Generalized autoregressive conditional heteroskedasticity. Journal of Econometrics, 31(3), 307327. https://doi.org/10.1016/0304-4076(86)90063-1

Bollerslev, T., Cai, J., \& Song, F. M. (2000). Intraday periodicity, long memory volatility, and macroeconomic announcement effects in the US Treasury bond market. Journal of Empirical Finance, 7(1), 37-55. https://doi.org/10. 10 16/S0927-5398(00)00002-5

Bourgoin, F. (2001). Stress-testing correlations: An application to portfolio risk management. In C. Dunis, A. Timmermann \& J. Moody (Ed.), Developments in forecast combination and portfolio choice, New York: Wiley.

Campbell, J. Y., \& Hentschel, L. (1992). No News is Good News: An Asymmetric Model of Changing Volatility in Stock Returns. Journal of Financial Economics, 31(3), 281-318. https://doi.org/10.1016/0304-405X(92)90037-X

Cambell, R., Koedijk, K., \& Kofman, P. (2002). Increased Correlation in Bear Markets. Financial Analysts Journal, 58 (1), 87-94. https://doi.org/10.2469/faj.v58.n1.2512

CBOE, (2009). CBOE S\&P 500 Implied Correlation Index. Available from: https://www.cboe.com/micro/ impliedcorrelation/impliedcorrelationindicator.pdf.

Cheng, W. H., \& Hung, J. C. (2011). Skewness and leptokurtosis in GARCH-typed VaR estimation of petroleum and metal asset returns. Journal of Empirical Finance, 18 (1), 160-173. https://doi.org/10.1016/j.jempfin.2010.05.004

Cotter, J., \& Longin, F. (2011). Implied correlation from VaR. MPRA Paper 3506, University Library of Munich, Germany. Available from: https://mpra.ub.uni-muenchen.de/3506/.

Dai, W., Xie, D., \& Sun, B. (2015). Intraday Periodicity and Long Memory Volatility in Hong Kong Stock Market. Open Journal of Social Sciences, 3(7), 61-66. https://doi.org/ 10.4236/jss.2015.37011 
Daouck, H., \& Ng, D. (2011). Is unlevered firm volatility asymmetric? Journal of Empirical Finance, 18(4), 634-651. https://doi.org/10.1016/j.jempfin.2011.05.003

Driessen, J., Maenhout, P. J., \& Vilkov, G. (2009). The Price of Correlation Risk: Evidence from Equity Options. The Journal of Finance, 64(3), 1377-1406. https://doi.org/10.1111/j.1540-6261.2009.01467.x

Elton, E. J., \& Gruber, M., J. (1973). Estimating the Dependence Structure of Share Prices - Implications for Portfolio Selection. Journal of Finance, 28(5), 1203-1232. https://doi.org/10.1111/j.1540-6261.1973.tb01451.x

Engle, R. F. (1982). Autoregressive Conditional Heteroscedasticity with Estimates of the Variance of United Kingdom Inflation. Econornetrica, 50(4), 987-1007. https://doi.org/10.2307/1912773

Engle, R. F. (2002). Dynamic Conditional Correlation. A Simple Class of Multivariate GARCH Models. Journal of Business and Economic Statistics, 20(3), 339-350. https://doi.org/10.1198/073500102288618487 339

Engle, R., \& Kelly, B. (2012). Dynamic Equicorrelation. Journal of Business \& Economic Statistics, 30(2), $212-228$. https://doi.org/10.1080/07350015.2011.652048

Engle, R. F., \& Ng, V. K. (1993). Measuring and Testing the Impact of News on Volatility. The Journal of Finance, 48(5), 1749-1778. https://doi.org/10.1111/j.1540-6261.1993.tb05127.x

Fink, H., \& Geppert, S. (2016). Implied correlation indices and volatility forecasting. Applied Economics Letters, 24(9), 1-5. https://doi.org/10.1080/13504851.2016.1213357

Girard, E., \& Biswas, R. (2007). Trading Volume and Market Volatility: Developed versus Emerging Stock Markets. Financial Review, 42(3), 429-459. https://doi.org/10.1111/j.1540-6288.2007.00178.x

Glosten, L. R., Jagannathan, R., \& Runkle, D. E. (1993). On the Relation between the Expected Value and the Volatility of the Nominal Excess Return on Stocks. Journal of Finance, 48(5), 1779-1801. https://doi.org/10.2307/2329067

Granger, C. W. J. (1969). Investigating Causal Relations by Econometric Models and Cross-spectral Methods. Econometrica, 37(3), 424-438. https://doi.org/10.2307/1912791

Hansen, P. R., \& Lunde, A. (2005). A forecast comparison of volatility models: does anything beat a GARCH (1, 1)? Journal of applied econometrics, 20(7), 873-889. https://doi.org/10.1002/jae.800

Hull, J., \& White, A. (1998). Incorporating volatility updating into the historical simulation method for VaR. Journal of Risk, 1(1), 5-19. https://doi.org/10.21314/JOR.1998.001

Hardle, W. K., \& Silyakova, E. (2014). Implied Basket Correlation Dynamics. Statistics \& Risk Modelling, 33(1-2). Available from SSRN: https://ssrn.com/abstract=2729248. https://doi.org/10.1515/strm-2014-1176

Just, M. (2014). The use of Value-at-Risk models to estimate the investment risk on agricultural commodity market. Economic Development and Management of Regions, Hradec Kralove, Peer-Reviewed Conference Proceedings, 264-273. Available from: https://uni.uhk.cz/hed/site/assets/files/1049/proceedings_2014_4.pdf.

Lamoureux, C. G., \& Lastrapes, W. D. (1990). Persistence in Variance, Structural Change, and the GARCH Model. Journal of Business \& Economic Statistics, 8(2), 225-234. https://doi.org/10.1080/07350015.1990.10509794

Ledoit, O., \& Wolf, M. (2003). Improved Estimation of the Covariance Matrix of Stock Returns with an Application to Portfolio Selection. Journal of Empirical Finance, 10(5), 603-621. https://doi.org/10.1016/S0927-5398(03)00007-0

Liu, J. (2016). A New Tail-based Correlation. Allen Institute, Working Paper.

Longin, F., \& Solnik, B. (1995). Is correlation in international equity markets constant: 1960-1990? Journal of International Money and Finance, 14, 3-26. https://doi.org/ 10.1016/0261-5606(94)00001-H

Longin, F., \& Solnik, B. (2001). Extreme correlation of international equity markets. The Journal of Finance, 56(2), 649676. https://doi.org/10.1111/0022-1082.00340

Marimoutou, V., Raggad, B., \& Trabelsi, A. (2009). Extreme Value Theory and Value at Risk: Application to Oil Market. Energy Economics, 31, 519-530. https://doi.org/10.1016/j.eneco.2009.02.005

Markowitz, H. (1952). Portfolio Selection. The Journal of Finance, 7(1), 77-91. https://doi.org/10.1111/j.15406261.1952.tb01525.x

McNeil, A. J., Frey, R., \& Embrechts, P. (2005). Quantitative risk management: concepts, techniques and tools. Princeton: Princeton University Press.

Mittnik, S. (2014). VaR-implied tail-correlation matrices. Economics Letters, 122(1), 69-73. https://doi.org/10. 1016/j. econlet.2013.10.025

Naik, P. K., \& Padhi, P. (2015). Stock Market Volatility and Equity Trading Volume: Empirical Examination from Brazil, Russia, India and China (BRIC). Global Business Review, 16(5), 28S-45S. https://doi.org/10.1177/09721 50915601235 
Krzysztof Echaust, Malgorzata Just. Implied Correlation Index: an Application to Economic Sectors of Commodity Futures...

Nelson, D. B. (1991). Conditional Heteroskedasticity in Asset Returns: A New Approach. Econometrica, 59 (2), $347-$ 370. https://doi.org/10.2307/2938260

Osinska, M. (2008). Econometric Analysis of Causal Relationships (in Polish). Torun: Nicolaus Copernicus University of Torun.

Ramchand, L., \& Susmel R. (1998). Volatility and cross correlation across major stock markets. Journal of Empirical Finance, 5, 397-416. https://doi.org/10.1016/S0927-5398(98)00003-6

Sandoval Jr., L., \& Franca, I. (2012). Correlation of financial markets in times of crisis. Physica A: Statistical Mechanics and its Applications, 391(1-2),187-208. https://doi.org/10.1016/j.physa.2011.07.023

Siegel, A. F. (1997). International currency relationship information revealed by cross-option prices. Journal of Futures Markets, 17(4), 369-384. https://doi.org/10.1002/(SICI)1096-9934(199706)17:4<369::AID-FUT1>3.0.CO;2-F

Skintzi, V. D., \& Refenes A. P. (2005). Implied correlation index: a new measure of diversification. Journal of Futures Markets, 25(2), 171-197. https://doi.org/10.1002/fut.20137

Solnik, B., Bourcell, C., \& Le Fur, Y. (1996). International Market Correlation and Volatility. Financial Analysts Journal, 5, 17-34. https://doi.org/10.2469/faj.v52.n5.2021

Walter, C. A., \& Lopez, J. A. (2000). Is implied correlation worth calculating? Evidence from foreign exchange options. The Journal of Derivatives, 7(3), 65-81

Wanat, S., Papiez, M., \& Smiech, S. (2015). The Conditional Dependence Structure between Precious Metals: A CopulaGARCH Approach. Cracow Review of Economics and Management, 4(940), 19-33. https://doi.org/10.15678/ ZNUEK.2015.0940.0402

Zhou, H. (2013). On the predictive power of the implied correlation index. Working Paper. Available from: https://www2.bc.edu/hongtao-zhou/JMP.pdf.

The article has been reviewed.

Received in December 2018; accepted in February 2020. 